\title{
Geopolymers based on some clay from Burkina Faso: preparation and characterization
}

\section{Soungalo Ouattara ${ }^{1}$, Brahima Sorgho ${ }^{1}$, Lamine Zerbo ${ }^{1 *}$, Youssouf Sawadogo ${ }^{1}$, Moustapha Sawadogo ${ }^{1}$, Mohamed Seynou ${ }^{1}$, Philippe Blanchart ${ }^{2}$}

${ }^{1}$ Laboratoire de Chimie Moléculaire et des Matériaux (LCMM), University Joseph KI-ZERBO, Burkina Faso. BP 7021 Ouagadougou 03

${ }^{2}$ Institut of Research in Ceramique (IRCER), UMR-CNRS 7315, Centre Européen de la Céramique, 12, rue Atlantis, 87068 Limoges, Cedex, France

lamine_zerbo@yahoo.fr

Geopolymers based on clay materials from Burkina Faso were developed and then characterized for use in building. The results of the characterization of the clay mineral material referenced TAN as well as its calcined forms have shown by several analysis techniques (XRD, IR, ICP-AES) that TAN contains kaolinite (71\%), quartz (20\%), illite (4\%) and goethite (2\%). TAN clay and its calcined forms are each mixed with the alkaline solution (sodium hydroxide solution $8 \mathrm{~mol}^{-1}$ ) in a mass ratio (alkaline solution/clay) ranging from 0.33 to 0.36 . The results of the mechanical and mineralogical tests of the geopolymers produced showed that GP-MK $\mathrm{M}_{0}$ produced had the best performance favorable for its use in construction. Indeed, its linear shrinkage (3.44\%) is low and the compressive strength $(22.50 \mathrm{MPa})$ is greater than $4 \mathrm{MPa}$. This performance of $\mathrm{GP}^{-} \mathrm{MK}_{0}$ is due to the formation of a phase rich in silica and alumina $\left(\mathrm{Na}_{2}\left(\mathrm{AlSiO}_{4}\right)_{6}(\mathrm{OH})_{2} .2 \mathrm{H}_{2} \mathrm{O}\right)$.

Keywords : Clay; development; geopolymer; characterization; building. 